\title{
Induction and comparison of craving for tobacco, marijuana and crack
}

 \\ Alexandre Dido Balbinot 5 , Vinícius Jobim Fischer 2 , Ana Cecília Petta Roselli Marques 6
}

1 São Pedro Mental Hospital, Porto Alegre, RS, Brazil.

2 Faculty of Psychology, Pontifical Catholic University of Rio Grande do Sul (PUCRS), Porto Alegre, RS, Brazil.

${ }^{3}$ Center for Drug and Alcohol Research, Federal University of Rio Grande do Sul (UFRGS), Porto Alegre, RS, Brazil.

${ }_{4}^{4}$ Cognitive and Behavioral Center for Research and Intervention, Faculty of Psychology and Educational Sciences, University of Coimbra, Coimbra, Portugal.

5 Unisinos University, São Leopoldo, RS, Brazil.

${ }^{6}$ Brazilian Association of Alcohol and Other Drugs Study, and the Federal University of São Paulo (Unifesp), São Paulo, SP, Brazil.

Received: 9/10/2015 - Accepted: 10/19/2015

DOI: 10.1590/0101-60830000000061

\begin{abstract}
Background: The literature findings report that use of multiple substances can produce adverse clinical and behavioral effects, which may affect craving and the results of drug treatment. Also, the understanding of craving construct and its interaction in the use of smoked substances is underexplored. Objectives: To induce and compare craving for tobacco, marijuana and crack-cocaine on hospitalized dependents whose drug of choice is crack-cocaine. Methods: Quasi-experimental study with a convenience sample consisting of 210 males divided into 3 equal groups (Group-1: craving induced by crack; Group-2: craving induced by tobacco; and Group-3: craving induced by marijuana). All participants met ICD-10 dependence criteria for cocaine/crack, marijuana and tobacco, were aged between 18 and 65 and had used these substances for at least one year. Photos were used to induce craving and self-report instruments to evaluate possible alterations. Results: This study showed that craving for tobacco was more intense than for marijuana and crack, when the groups were compared by VAS. Using specific scales, both craving for tobacco and craving for marijuana were more intense than craving for crack. Discussion: These results would imply interventions at the initial stages of abstinence with cognitive-behavioural techniques and pharmacotherapy in order to reduce craving.
\end{abstract}

Araujo RB et al. / Arch Clin Psychiatry. 2015;42(5):117-21

Keywords: Craving, tobacco, marijuana, crack cocaine, multiple dependence.

Craving is an important concept in the area of drug dependence and has been discussed for more than a century; Merck's Manual of the Materia Medica ${ }^{1,2}$ had, in 1899 , already proposed that cocaine be used to relieve craving for alcohol, demonstrating one of the first attempts to "medicate" craving. In 1954, at a meeting of experts from the World Health Organization ${ }^{3}$, Jellineck, among others, concluded that the term "craving" was scientifically inaccurate, as it referred only to an urgent and intense desire. The group therefore decided to replace "craving" for physical dependence - in cases of craving related to withdrawal symptoms - and pathological desire - in cases of desire occurring after a longer period of abstinence 4 . Isbell ${ }^{5}$ emphasized that craving was very difficult to define as it could mean different things to different people.

Currently, different concepts of craving can be verified. These range from the best known "intense desire to consume a particular substance" 6 to one that encompasses not only the desire but also "the expectation of a positive effect, the relief of withdrawal symptoms and negative affect and the intention to use the drug" 7 . Rankin et al. ${ }^{8}$ argued that craving is a multi-dimensional construction and must therefore involve physiological, psychological and behavioural aspects.

Despite the importance of this issue, there is little research analysing and comparing craving for psychoactive substances. Tiffany et al. ${ }^{9}$ considered, for example, that craving for cocaine was related to a different area than that experienced by tobacco ${ }^{7}$ : the lack of control; however no research was conducted to prove this difference. On the other hand some studies have demonstrated evidence that craving for tobacco and smoked cocaine (crack) are associated ${ }^{10}$ and that exposure to nicotine can increase cocaine self-administration ${ }^{11}$ as well as trigger its craving, especially among crack users ${ }^{12}$.

Regarding craving for marijuana, on one hand, one study 13 verified that $93 \%$ of marijuana dependents reported only a mild craving for the substance whereas, another research ${ }^{14}$ observed that dependents reported a more intense craving than cocaine dependents. Budney et al. ${ }^{15}$ when comparing craving for marijuana and tobacco, found that craving for tobacco was slightly more intense.

The literature findings report that cocaine/crack dependents have a history of other psychoactive substances use ${ }^{10}$ and that such use of multiple drugs can produce adverse clinical and behavioural effects, cumulative and synergistic, via interaction between the substances, which may affect craving and the results of drug treatment ${ }^{16}$. Because of the need to better understand the craving construct and its interaction in the use of smoked substances, the purpose of this article is to induce and compare craving for tobacco, marijuana and cocaine (crack) on hospitalized dependents whose drug of choice is crack.

\section{Methods}

\section{Design}

This is a quasi-experimental study.

\section{Participants}

The subjects were chosen "by convenience" which is defined ${ }^{17}$ as a means of selecting data on which there is a no statistical randomness but a value judgment, for example, subjects' accessibility as a criterion. The sample consisted of 210 male subjects, admitted to the specialized chemical dependency unit of the São Pedro Psychiatric Hospital (Porto Alegre - RS), divided into 3 groups each comprising 70 subjects. Group 1 (induced craving for crack), group 2 (induced craving for tobacco) and group 3 (induced craving for marijuana). 


\section{Inclusion criteria}

Fulfil ICD-1018 dependence criteria for cocaine/crack, marijuana and tobacco. Been using these substances for at least one year, with a minimum education level of fifth-grade elementary school and aged between 18 and 65 years old. Participants must have been abstinent for a period of 7-21 days. All were undergoing Nicotine Replacement Therapy (transdermal $21 \mathrm{mg}$ ) - which is part of the inpatient unit treatment protocol - and were using psychiatric medication. The inclusion of the subject in the study was only done if cocaine/crack was their "drug of choice" (favourite), since it is difficult to observe cocaine/crack dependents that do not use other substances. This criterion had already been used in previous studies 9,19 .

\section{Exclusion criteria}

Presenting psychotic symptoms, acute symptoms of mood disorder (assessed by the SRQ-20; Mari \& Williams, 1986), being dependent on other substances or having cognitive impairments that altered performance in the tests according to the Mini-Mental State Examination ${ }^{20}$.

\section{Instruments}

\section{Demographics and substance use}

Form with socio-demographic data and information related to pattern of psychotropic substance consumption.

\section{Cognitive level}

Mini-Mental State Examination (MMSE) 20 - screening test to assess cognitive level at the time of the interview. $25 / 30$ points suggests commitment, and $<20$ points indicates, with certainty, that there is cognitive impairment ${ }^{21}$. For this research a cut-off point below 25 points was used to exclude patients with cognitive impairment from the sample group.

\section{Presence of psychotic symptoms}

SRQ-20 - A scale previously validated in Brazil22, which screened the general population and classified adults either as neurotic $(>7)$, who could participate in the study, or psychotic $(>1)$, who were excluded.

\section{Severity of dependence}

Severity of Tobacco, Cocaine/Crack and Marijuana dependence - as there are no validated instruments to assess the severity of dependence on Cocaine/Crack and Marijuana, only on tobacco, in order to standardize the assessment of the severity in all groups, their weekly consumption was taken as a parameter.

\section{Anxiety symptoms}

Beck Anxiety Inventory (BAI) ${ }^{23}$ : this is a scale that measures the severity of anxiety symptoms. It consists of 21 questions in which the subject must grade on a four point scale. The total score is obtained by summing the individual scores of each question. The cut-offs for psychiatric patients, according to the norms of the Portuguese version, are: $0-10=$ minimal, $11-19=$ mild, $20-30=$ moderate and $31-63=$ severe $^{24}$. This will be administered to the three groups of participants.

\section{Depression symptoms}

Beck Depression Inventory (BDI)25: is designed for measuring the severity of depression, both in psychiatric patients and in the general population. It consists of 21 multiple-choice questions, each with four alternatives; the subject must choose the most applicable feeling at that moment. The total score is the sum of the points. The cut-offs for psychiatric patients were published in 2001 along with the Portuguese version by Cunha: $0-11=$ minimal $12-19=$ mild, $20-35=$ moderate and $36-63=$ severe $^{24}$.

\section{Craving intensity}

Visual Analogue Scale (VAS) - to assess craving this will be administered to all three groups, the individual will be asked to give their craving a grade, where 0 (zero) is the minimum grade (has no craving) and 10 the maximum (presents a very strong craving), this value is marked on a $10 \mathrm{~cm}$ scale. Several authors have used the Visual Analogue Scale to assess craving in their research ${ }^{26-29}$.

\section{Cocaine craving}

Cocaine Craving Questionnaire Brief (CCQ-Brief) ${ }^{19}$ : 10 scale statements compiled from the 45 statements Cocaine Craving Questionnaire - Now 9 . The CCQ-Brief is a Likert 7-point scale ranging from "strongly disagree" to "strongly agree". The CCQ-Brief and its version adapted for crack were validated in Brazil ${ }^{30-31}$. The score of the CCQBrief - Adapted Brazilian version for Crack is obtained from the total sum of the points (with the statements 4 and 7 reversed should be added to the other); from Factor 1 (points) - on the craving itself (the sum of all issues except 4 and 7) and Factor 2 - associated with lack of control of crack use (sum of questions 4 and 7 inverted). The cut-offs in the Brazilian version, for the total scale points, are: $0-11$ points, minimum craving; 12 to 16 , mild; $17-22$, moderate; and 23 or more points, intense craving. This questionnaire will only be applied to Group 1 .

\section{Tobacco craving}

Questionnaire of Smoking Urges Brief - Brazilian Version - QSU-B 32 - is an abbreviated scale developed by Cox et al. ${ }^{33}$ from the Questionnaire of Smoking Urges (QSU)7 used to assess craving for tobacco. It is comprised of 10 affirmative statements, to which the individual must state their position using a Likert 7-point scale ranging from "strongly disagree 'to' strongly agree". The QSU-B in its Brazilian validation ${ }^{32}$ can be analysed by the sum total of points and by the points of factor 1 related to craving for the positive reinforcing properties of tobacco (statements 1, 3,7 and 10) and by factor 2 related to craving of the negative reinforcing properties of this substance (statements 4,8 and 9). The cut-offs in the Brazilian version for the scale points total are: $0-13$ points, minimum craving; $14-26$, light; $27-42$, moderate; and 43 or more points, intense craving. This questionnaire will only be applied to Group 2.

\section{Marijuana craving}

Marijuana Craving Questionnaire - Short Form - MCQ-SF34 - It is a self-reporting scale of 12 items, using Likert 7 points ranging from "strongly disagree" to "strongly agree". It is an abbreviated version of the MCQ ${ }^{35}$, a multidimensional scale of 47 items. In Brazil, the semantic validation was made by Pedroso et al. ${ }^{36}$. In his psychometric ${ }^{37}$ the MCQ-SF was divided into three factors: Emotionality (questions 1, 9 and 11), Intentionality (questions 3 and 10) and Compulsivity (questions 2 and 7) and may be analysed in addition to the method of the points in each factor by the sum of the total points (of 12 questions). The cut-off points in the Brazilian version for the total of the scale points are: $0-23$ points, minimum craving; $24-38$, light; 39-53, moderate; and 54 or more points, intense craving. This will only be applied to Group 3.

\section{Materials to induce craving}

$1 / 4$ A4 size images of marijuana, crack cocaine and tobacco. Before being employed in this research the photos were considered faithful substance representations, with the potential to elicit craving, by a group of 20 hospitalized patients. 


\section{Ethical aspects}

Data collection was only initiated after the research project had been approved by the Research Ethics Board of São Pedro Psychiatric Hospital. Before participants were accepted to be part of the research project its purpose was explained to them and they were provided with a written informed consent, which was read with the individual and any possible doubts clarified. The signing of this form was a precondition for the participant to be included in the sample. This research was also conducted in accordance with the Helsinki Declaration as revised 1989.

\section{Procedures for data collection}

Each participant who fulfilled the inclusion criteria was sent individually to a room where an assessment interview was conducted and a record containing socio-demographic data and pattern of psychoactive substance consumption was completed. The SRQ-20, on how they felt at that moment was administered its diagnosis evaluated using ICD-10. During the experimental study, we recorded the period of abstinence from the last crack, tobacco or marijuana consumption, which determined whether the participant would be part of Group 1, 2 or 3 (if evaluated to be part of the marijuana group they would go there, if possible, if not they would go to another group with priority given to the group with less participants).

After deciding into which group the participant would be placed, they were individually shown, for 3 minutes, a photo of the desired craving (crack, tobacco or marijuana) related to their group after which other evaluation instruments were administered in the following order: CCQ-Brief (only for patients in Group 1), QSU-B (only for patients in Group 2), MCQ-SF (only for patients in Group 3), VAS, BAI and BDI (for all groups).

\section{Data analysis}

The data collected was processed in the SPSS statistics software (v.20; SPSS Inc., Chicago, IL). Exploratory data analysis consisted of descriptive and frequency statistical tests. The inferential analysis employed the tests: Chi-squared and Analysis of Variance (ANOVA) with Tukey's test. As the QSU-B and CCQ-Brief scales have ten statements each but the MCQ-SF has twelve, the following calculation: "Total points MCQ-SF/12 x 10" was used to allow different substance craving results to be compared. The result of this calculation and the raw scores of the QSU-B and CCQ-Brief will be presented in table 1. The significance level used as a parameter was $5 \%$.

\section{Results}

Each of the three groups was composed of 70 participants, regarding marital status, in accordance with the chi-squared test, there was no significant difference between groups $(\chi 2=8.217 ; p=0.223)$, with a prevalence of singles: $74.3 \%(n=52)$ in the Crack Group, $80.0 \%(n=$ $56)$ in the Marijuana Group and 67.1\% $(n=47)$ in the Tobacco Group. Group comparison regarding other socio-demographic variables, patterns of substance use and symptoms of depression and anxiety can be seen in table 2 .

The comparison of craving in the three groups via the Visual Analogical Scale and other Scales to assess craving (CCQ-Brief, QSU-B and MCQ-SF), can be seen in table 1. In both tables, ANOVA with Tukey's test was used.

Table 3 shows the severity of craving according to the analysis of the total of points from the scales and according to the points of its factors considering its cut-offs, which were published in their respective psychometric validation.

\section{Discussion}

When analysing the results of this study, it was observed that the marijuana group was younger, had first begun by using alcohol (earlier than the tobacco group), had used crack and inhaled cocaine (earlier than the other two groups) and had spent less time without using inhaled cocaine (compared to the tobacco group) and without using marijuana (than either of the other two groups). In addition, they used an extreme amount of marijuana (about 30 joints per week), independent of this variable there didn't appear a significant difference in the three groups. Such findings may be due to the convenience sample since most patients stopped using marijuana for a period greater than 21 days and before hospital admission (an inclusion criteria). Those who remain using marijuana seem to have a more serious drug use profile, which may have interfered with the craving. This result associated with the interruption of marijuana use, well before hospitalization, had already been highlighted in previous studies ${ }^{38,39}$ while researching crack addicts hospitalized for detoxification.

The Tobacco group was hospitalized for some time, but this difference did not affect the results, since the controlled variable was time in abstinence and not length of hospitalization and, the tendency of smokers to continue using tobacco. The Crack group used higher amounts of inhaled cocaine than the tobacco group, however, patients tended to be abstinent from this form of cocaine use during hospitalization, which cannot be taken as an intervening variable when comparing craving in the three groups. The interruption of inhaled cocaine when given crack was discussed by Balbinot and Araujo ${ }^{38}$.

The abstinent period of marijuana, however, may have affected the intensity of craving, but this variable cannot be controlled because of the characteristic of the sample, who had - as observed in other studies $^{38,39}$ - a longer period abstinent from marijuana. However, the association between the length of abstinence of marijuana and craving was not found in a previous study ${ }^{37}$.

There was no significant difference in the three groups for symptoms of depression and anxiety, mental states that could have interfered with craving, as already highlighted in other studies $7,31-32,40-42$.

When comparing craving using the Visual Analogue Scale, the tobacco group demonstrated a more intense craving than the other groups; however when the specific assessing scales for craving were used, the tobacco and marijuana groups had a more intense craving than the crack group. That the craving result for marijuana is more intense than for crack resembles the one found by McRae et al. ${ }^{14}$, however, with respect to inhaled cocaine it contrasts with another study ${ }^{13}$ which didn't find an intense craving for marijuana.

The more intense tobacco craving, than that for other substances, might be associated with the fact that many patients - contrary to what occurs with crack - are not motivated to stop using this substance, this association had already been emphasized ${ }^{43}$. Haller et al. ${ }^{44}$ also observed this phenomenon while researching the motivation for change in female smokers, however, it should be noted that other studies found no correlation between craving and motivation for change in smokers ${ }^{32,40}$, which means this would be just one of the aspects to explain this finding, since dependence, abstinence and all corresponding phenomena with craving have multifactorial etiology.

Analysing craving for the three substances from their sub-factors, adding the rates of moderate and severe degrees, it can be observed that factor 2 of craving for crack (which refers to uncontrolled crack use), the emotionality factor craving for marijuana and factor 2 (negative reinforcing capacity) the craving for tobacco had higher scores. These results demonstrate that craving associated with the use of the substance for the relief of negative affect (such as anxiety and depression) or withdrawal symptoms was more intense than that for obtaining pleasure (positive reinforcement). The relevance, in this sample, of emotional aspects and negative reinforcing potential of substances to induce craving had already been verified in research concerning the craving for tobacco ${ }^{7,43}$, and marijuana ${ }^{37}$.

Limitations of this study are related to their possible interference with craving. They are: the large average amount of marijuana used by the three groups, the length of marijuana abstinence (which is higher in the marijuana group), the fact that psychiatric medication was not controlled 45 and the motivation to change addictive behaviour not being assessed; which mainly may have affected the tobacco craving values ${ }^{43,44}$, which most patients did not intend to stop after hospitalization. 
Table 1. Comparison of the averages in the three groups of scores on the craving scales

\begin{tabular}{|c|c|c|c|c|c|c|c|c|c|c|c|c|c|c|}
\hline \multirow[t]{2}{*}{ Variable } & \multicolumn{3}{|c|}{ Total Sample } & \multicolumn{3}{|c|}{ Group 1-Crack } & \multicolumn{3}{|c|}{ Group 2-Marijuana } & \multicolumn{3}{|c|}{ Group 3-Tobacco } & \multicolumn{2}{|c|}{ ANOVA } \\
\hline & $\mathrm{M}(\mathrm{SD})$ & Min & Max & $\mathrm{M}(\mathrm{SD})$ & Min & Max & $\mathrm{M}(\mathrm{SD})$ & Min & Max & $\mathrm{M}(\mathrm{SD})$ & Min & Max & $\mathrm{F}$ & $p$-value \\
\hline $\begin{array}{l}\text { Craving according to } \\
\text { Visual Analogic Scale }\end{array}$ & 3.41 (3.39) & 0 & 10 & $2.39(2.82)^{a}$ & 0 & 10 & $3.15(2.27) \mathrm{a}$ & 0 & 10 & $4.71(3.64)^{b}$ & 0 & 10 & 9.287 & $<0.001$ \\
\hline $\begin{array}{l}\text { Craving according to } \\
\text { specifics scales for each } \\
\text { group }\end{array}$ & $28.60(17.31)$ & 10 & 70 & 19.68 (11.49)a & 10 & 55 & $32.26(15.86)^{b}$ & 10 & 64.17 & $33.70(20.12)^{b}$ & 10 & 70 & 16.683 & $<0.001$ \\
\hline
\end{tabular}

M: means; SD: standard deviation; Min: minimum; Max: maximum; a. b: means significant differences according to the Tukey's test; F: F-ratio test.

Table 2. Sample characteristics regarding sociodemographic variables, pattern of use of substances and symptoms of depression and anxiety

\begin{tabular}{|c|c|c|c|c|c|c|c|c|c|c|c|c|c|c|}
\hline \multirow{3}{*}{ Variable } & \multirow{2}{*}{\multicolumn{3}{|c|}{$\begin{array}{c}\text { Total Sample } \\
(\mathrm{n}=210)\end{array}$}} & \multirow{2}{*}{\multicolumn{3}{|c|}{$\begin{array}{c}\text { Group 1-Crack } \\
(n=70)\end{array}$}} & \multirow{2}{*}{\multicolumn{3}{|c|}{$\begin{array}{c}\text { Group 2-Marijuana } \\
(n=70)\end{array}$}} & \multirow{2}{*}{\multicolumn{3}{|c|}{$\begin{array}{c}\text { Group 3- Tobacco } \\
\qquad(\mathrm{n}=70)\end{array}$}} & \multirow{2}{*}{\multicolumn{2}{|c|}{ ANOVA }} \\
\hline & & & & & & & & & & & & & & \\
\hline & $\mathrm{M}(\mathrm{SD})$ & Min & Max & $\mathrm{M}(\mathrm{SD})$ & Min & Max & $\mathrm{M}(\mathrm{SD})$ & Min & Max & $\mathrm{M}(\mathrm{SD})$ & Min & Max & $\mathrm{F}$ & $p$-value \\
\hline Age & $28.02(7.41)$ & 18 & 50 & $29.35(6.82)^{\mathrm{a}}$ & 18 & 49 & $25.89(7.26)^{b}$ & 18 & 50 & $28.89(7.73)^{a}$ & 18 & 48 & 4.671 & 0.010 \\
\hline Years of Education & $7.93(2.37)$ & 5 & 15 & $7.96(2.28)$ & 5 & 14 & $8.14(2.61)$ & 5 & 15 & $7.70(2.37)$ & 5 & 15 & 0.621 & 0.538 \\
\hline Days of hospitalization & $8.68(3.92)$ & 2 & 30 & $8.04(3.79) \mathrm{a}$ & 2 & 30 & $8.33(3.74)^{a}$ & 2 & 20 & $9.64(4.08)^{b}$ & 2 & 27 & 345 & .037 \\
\hline Age at first use of crack & $21.39(6.39)$ & 10 & 48 & $22.94(6.58)^{a}$ & 10 & 48 & $19.15(5.31)^{\mathrm{b}}$ & 12 & 35 & $22.09(6.65)^{\mathrm{a}}$ & 13 & 45 & 6.864 & 0.001 \\
\hline $\begin{array}{l}\text { Amount of crack use (in } \\
\text { rocks)/week }\end{array}$ & 23.02 (27.37) & 1 & 168 & $24.97(30.66)$ & 1 & 168 & $25.03(28.10)$ & 2 & 140 & $19.04(22.67)$ & 1 & 112 & 1.060 & 0.348 \\
\hline Last use of crack (days) & 55.87 (303.96) & 1 & 3600 & $9.54(3.79)$ & 7 & 21 & $38.58(129.45)$ & 1 & 780 & 138.54 (555.58) & 4 & 3600 & 2.639 & 0.074 \\
\hline Age at first cocaine use & $16.75(3.08)$ & 10 & 35 & $17.05(2.41)^{a}$ & 13 & 25 & $15.73(2.42)^{b}$ & 10 & 25 & $17.42(3.94)^{\mathrm{a}}$ & 11 & 35 & 5.236 & 0.006 \\
\hline $\begin{array}{l}\text { Amount of cocaine } \\
\text { grams/week }\end{array}$ & $11.67(20.12)$ & 0 & 140 & $17.60(24.97)^{a}$ & 0 & 100 & $9.74(20.23)$ ab & 0 & 140 & $7.80(12.05)^{b}$ & 0 & 70 & 53 & 021 \\
\hline $\begin{array}{l}\text { Last use of cocaine/ } \\
\text { days }\end{array}$ & $\begin{array}{c}576.14 \\
(1208.89)\end{array}$ & 2 & 7300 & $\begin{array}{c}631.09 \\
(1078.60)^{\text {ab }}\end{array}$ & 2 & 5040 & $277(759.21)^{b}$ & 6 & 5400 & $912.49(1667.36)^{a}$ & 10 & 7300 & 3.400 & 0.036 \\
\hline $\begin{array}{l}\text { Age at first use of } \\
\text { marijuana }\end{array}$ & $15.06(3.05)$ & 9 & 30 & $15.46(3.51)$ & 10 & 30 & 4) & 9 & 20 & 8) & 9 & 24 & 452 & 0.089 \\
\hline $\begin{array}{l}\text { Amount of marijuana } \\
\text { cigarette/week }\end{array}$ & $24.35(28.71)$ & 1 & 160 & $22.59(2$ & 1 & 140 & 30.0 & 2 & 160 & 19.8 & 1 & 140 & 2.365 & 0.097 \\
\hline $\begin{array}{l}\text { Last use of marijuana } \\
\text { (days) }\end{array}$ & $\begin{array}{c}357.21 \\
(1040.44) \\
\end{array}$ & 1 & 6480 & $\begin{array}{c}506.32 \\
(1121.44)^{\mathrm{a}} \\
\end{array}$ & 2 & 5040 & $10(3.89)^{b}$ & 7 & 21 & $732.27(1508.07)^{\mathrm{a}}$ & 1 & 6480 & 7.822 & 0.001 \\
\hline Age at first tobacco use & $13.82(3.43)$ & 5 & 36 & $13.83(3.04)$ & 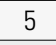 & 20 & $13.22(2.80)$ & 7 & 20 & $14.39(4.19)$ & 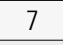 & 36 & 1.985 & 0.140 \\
\hline $\begin{array}{l}\text { Amount of tobacco } \\
\text { cigarettes/week }\end{array}$ & $\begin{array}{c}167.41 \\
(103.11) \\
\end{array}$ & 5 & 700 & $144.98(70.65)$ & 20 & 280 & $\begin{array}{c}181.88 \\
(127.07) \\
\end{array}$ & 5 & 700 & $173.86(100.10)$ & 5 & 560 & 2.351 & 0.098 \\
\hline $\begin{array}{l}\text { Last use of tobacco } \\
\text { (days) }\end{array}$ & 8.64 (3.49) & 0 & 20 & $8.31(3.20)$ & 2 & 15 & $8.73(4.01)$ & 0 & 20 & 8.84 & 7 & 16 & 0.343 & 0.710 \\
\hline Age at first alcohol use & $13.58(3.24)$ & 4 & 25 & $13.62(2.98)^{a b}$ & . & 20 & $12.84(3.52)^{a}$ & 5 & 25 & $14.26(3.10)^{b}$ & 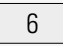 & 25 & 3.158 & 0.045 \\
\hline $\begin{array}{l}\text { Units of alcohol* use/ } \\
\text { week }\end{array}$ & $63.66(100.82)$ & 0.80 & 560 & $63.17(94.59)$ & 1 & 373 & $61.82(96.37)$ & 1 & 560 & $65.89(111.52)$ & 0.80 & 560 & 0.026 & 0.974 \\
\hline $\begin{array}{l}\text { Last use of alcohol } \\
\text { (days) }\end{array}$ & $89.22(355.85)$ & 1 & 4015 & $88.10(241.96)$ & 2 & 1440 & $40.03(100.11)$ & 1 & 540 & 155.67 (596.31) & 5 & 4015 & 1.392 & 0.252 \\
\hline BDI total & $15.93(11.10)$ & 0 & 55 & $14.23(8.83)$ & . & 37 & $17.82(12.48)$ & 0 & 55 & $15.69(11.47)$ & 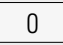 & 52 & 1.898 & 0.152 \\
\hline BAl total & $10.95(10.43)$ & 0 & 48 & $9.70(9.79)$ & 0 & 44 & $11.54(10.96)$ & 0 & 47 & $11.59(10.51)$ & 0 & 48 & 0.743 & 0.477 \\
\hline
\end{tabular}

M: means; SD: standard deviation; Min: minimum; Max: maximum; * Unit of alcohol: 10 grams of alcohol; a.b: means significant differences according to the Tukey's test; F: F-ratio test.

Table 3. Levels of craving for crack, marijuana and tobacco

\begin{tabular}{|c|c|c|c|c|c|c|c|c|}
\hline \multirow{3}{*}{ Variable } & \multicolumn{8}{|c|}{ Craving levels } \\
\hline & \multicolumn{2}{|c|}{ Minimum } & \multicolumn{2}{|c|}{ Mild } & \multicolumn{2}{|c|}{ Moderate } & \multicolumn{2}{|c|}{ Severe } \\
\hline & $\mathrm{n}$ & $\%$ & $\mathrm{n}$ & $\%$ & $\mathrm{n}$ & $\%$ & $\mathrm{n}$ & $\%$ \\
\hline CCQ-Brief Total & 23 & 32.9 & 14 & 20 & 15 & 21.4 & 18 & 25.7 \\
\hline Craving & 0 & 0 & 38 & 54.3 & 6 & 8.6 & 26 & 37.1 \\
\hline Lack of control & 27 & 38.6 & 5 & 7.1 & 4 & 5.7 & 34 & 48.6 \\
\hline MCQ-SF Total & 22 & 31.4 & 13 & 18.6 & 21 & 30 & 14 & 20 \\
\hline Emotionality & 15 & 21.4 & 19 & 27.1 & 18 & 25.7 & 18 & 25.7 \\
\hline Compulsivity & 0 & 0 & 50 & 71.4 & 6 & 8.6 & 14 & 20 \\
\hline Intentionality & 0 & 0 & 50 & 71.4 & 7 & 10 & 13 & 18.6 \\
\hline QSU-B Total & 14 & 20 & 17 & 24.3 & 15 & 21.4 & 24 & 34.3 \\
\hline Craving positive reinforcing & 16 & 22.9 & 18 & 25.7 & 12 & 17.1 & 24 & 34.3 \\
\hline Craving negative reinforcing & 0 & 0 & 23 & 32.9 & 23 & 32.9 & 24 & 34.3 \\
\hline
\end{tabular}

CCQ-Brief: Cocaine Craving Questionnaire-Brief; MCQ-SF: Marijuana Craving Questionnaire-Short Form; QSU-B: Questionnaire of Smoking Urges-Brief. 
Crack, marijuana and tobacco dependent patients have proven to have a more intense craving for tobacco measured by generic scale (Visual Analogue Scale), and for tobacco and marijuana measured by specific scales. Craving has been associated with relief of negative emotional symptoms (such as anxiety and depression). Thus, taking into account the patient's suffering in the initial phase of treatment - acute period of abstinence - and the high rates of emotional episodes, it is important to link the cognitive-behavioural techniques with pharmacotherapy to relieve craving.

\section{Acknowledgments}

This study has been funded by the Coordination for the Improvement of Higher Education Personnel (Capes) throughout a full doctorate abroad scholarship for the fourth author.

\section{Conflicts of interest}

The authors declare that there are no conflicts of interest regarding this manuscript.

\section{References}

1. Merck \& Co. Merck's Manual of the Materia Medica. New York: Merck \& Co.; 1898.

2. Addolorato G, Leggio L, Abenavoli L, Gasbarrini G; Alcoholism Treatment Study Group. Neurobiochemical and clinical aspects of craving in alcohol addiction: a review. Addict Behav. 2005;30(6):1209-24.

3. WHO Expert Committees on Mental Health and on Alcohol (1955). The 'craving' for alcohol. Q J Stud Alcohol. 1955;16:33-66.

4. Skinner MD, Aubin HJ. Craving's place in addiction theory: contributions of the major models. Neurosci Biobehav Rev. 2010;34(4):606-23.

5. Isbell $\mathrm{H}$. The "craving" for alcohol. Report of the WHO Expert Committee on Mental Health on Alcohol. Q J Stud Alcohol. 1955;16:38-41.

6. Kozlowski LT, Pillitteri JL, Sweeney CT, Whitfield KE, Graham JW. Asking questions about urges or cravings for cigarettes. Psychol Addict Behav. 1996;10:248-60.

7. Tiffany ST, Drobes DJ. The development and initial validation of a questionnaire on smoking urges. Br J Addict. 1991;86(11):1467-76.

8. Rankin H, Hodgson R, Stockwell T. The concept of craving and its measurement. Behav Res Ther. 1979;17(4):389-96.

9. Tiffany ST, Singleton E, Haertzen CA, Henningfield JE. The development of a cocaine craving questionnaire. Drug Alcohol Depend. 1993;34(1):19-28.

10. Zeni TC, Araujo RB. Relação entre o craving por tabaco e o craving por crack em pacientes internados para desintoxicação. J Bras Psiquiatr. 2011;60:28-33.

11. Horger BA, Giles MK, Schenk S. Preexposure to amphetamine and nicotine predisposes rats to self-administer a low dose of cocaine. Psychopharmacology (Berl). 1992;107(2-3):271-6.

12. Sees KL, Clark HW. When to begin smoking cessation in substance abusers. J Subst Abuse Treat. 1993;10(2):189-95.

13. Budney AJ, Vandrey RG, Hughes JR, Thostenson JD, Bursac Z. Comparison of cannabis and tobacco withdrawal: severity and contribution to relapse. J Subst Abuse Treat. 2008;35(4):362-8.

14. McRae AL, Hedden SL, Malcolm RJ, Carter RE, Brady KT. Characteristics of cocaine- and marijuana-dependent subjects presenting for medication treatment trials. Addict Behav. 2007;32(7):1433-40.

15. Budney AJ, Novy PL, Hughes JR. Marijuana withdrawal among adults seeking treatment for marijuana dependence. Addiction. 1999;94(9):1311-22.

16. Reid MS, Mickalian JD, Delucchi KL, Hall SM, Berger SP. An acute dose of nicotine enhances cue-induced cocaine craving. Drug Alcohol Depend. 1998;49(2):95-104.

17. Pereira MG. Epidemiologia - teoria e prática. Rio de Janeiro: Guanabara Koogan S.A.; 1995.

18. Organização Mundial de Saúde. Classificação de transtornos mentais e de comportamento da CID-10: Descrições clínicas e diretrizes diagnósticas. Porto Alegre: Artes Médicas; 1993.

19. Sussner BD, Smelson DA, Rodrigues S, Kline A, Losonczy M, Ziedonis D. The validity and reliability of a brief measure of cocaine craving. Drug Alcohol Depend. 2006;83(3):233-7.
20. Folstein MF, Folstein SE, McHugh PR. "Mini-mental state". A practical method for grading the cognitive state of patients for the clinician. J Psychiatr Res. 1975;12(3):189-98.

21. Kaplan H, Sadock B, Grebb J. A. Compêndio de Psiquiatria - Ciências do Comportamento e Psiquiatria Clínica. Porto Alegre: Artes Médicas; 1997.

22. Mari JJ, Williams P. A validity study of a psychiatric screening questionnaire (SRQ-20) in primary care in the city of Sao Paulo. Br J Psychiatry. 1986;148:23-6.

23. Beck AT, Steer RA. Beck Anxiety Inventory: Manual. San Antonio: Psychological Corporation; 1993.

24. Cunha JA. Manual da versão em português das Escalas Beck. São Paulo: Casa do Psicólogo; 2001.

25. Beck AT, Steer RA. Beck Depression Inventory: Manual San Antonio: Psychological Corporation; 1993.

26. Dols $M$, van den Hout M, Kindt M, Willems B. The urge to smoke depends on the expectation of smoking. Addiction. 2002;97(1):87-93.

27. Franken IH, Hendriksa VM, van den Brink W. Initial validation of two opiate craving questionnaires the obsessive compulsive drug use scale and the desires for drug questionnaire. Addict Behav. 2002;27(5):675-85.

28. Karg RS. The effects of stress and smoking related cues on craving to smoke among abstinent and non-abstinent cigarette smokers. Dissertation abstracts international: Section B. Sciences Engineering. 2002;63:3010.

29. Singleton EG, Anderson LM, Heishman SJ. Reliability and validity of the Tobacco Craving Questionnaire and validation of a craving-induction procedure using multiple measures of craving and mood. Addiction. 2003;98(11):1537-46.

30. Araujo RB, Pedroso RS, Castro MGT. Adaptação transcultural para o idioma português do Cocaine Craving Questionnaire - Brief. Rev Psiquiatr Clin. 2010;37:195-8.

31. Araujo RB, Castro MGT, Pedroso RS, Santos PL, Leite L, Rocha MR, et al. Validação psicométrica do Cocaine Craving Questionnaire-Brief - Versão Brasileira Adaptada para o Crack para dependentes hospitalizados. J Bras Psiquiatr. 2011;60:233-9.

32. Araujo RB, Oliveira MS, Moraes JFD, Pedroso RS, Port F, Castro MGT. Validação da versão brasileira do Questionnaire of Smoking Urges - Brief. Rev Psiquiatr Clin. 2007;34:166-75.

33. Cox LS, Tiffany ST, Christen AG. Evaluation of the brief questionnaire of smoking urges (QSU-brief) in laboratory and clinical settings. Nicotine Tob Res. 2001;3(1):7-16.

34. Heishman SJ, Evans RJ, Singleton EG, Levin KH, Copersino ML, Gorelick DA. Reliability and validity of a short form of the Marijuana Craving Questionnaire. Drug Alcohol Depend. 2009;102(1-3):35-40.

35. Heishman SJ, Singleton EG, Liguori A. Marijuana Craving Questionnaire: development and initial validation of a self-report instrument. Addiction. 2001;96(7):1023-34.

36. Pedroso RS, Castro MGT, Araujo RB. Marijuana Craving Questionnaire (MCQ-SF/Versão Brasil): validação semântica. J Bras Psiquiatr. 2009;58:218-22.

37. Pedroso RS, Castro MGD, Lucena-Santos P, Polese GP, Balbinot AD, Fischer VJ, et al. Validação Psicométrica do Marijuana Craving Questionnaire-Short Form - Versão Brasil. Clin Biomed Res. 2014;34:387-96.

38. Balbinot AD, Araujo RB. Análise do perfil de dependentes de crack em internação hospitalar. Saud Pesq. 2012;5:471-80.

39. Lewgoy LB, Fischer VJ, Oppermann CMO, Araujo RB. Padrão de uso de cannabis em pacientes dependentes de crack cocaína internados para desintoxicação. Clin Biomed Res. 2014;34:274-80.

40. Araujo RB, Oliveira MS, Mansur MA. Brazilian validation of the Questionnaire of Smoking Urges. Cad Saude Publica. 2006;22:2157-67.

41. Delfino RJ, Jamner LD, Whalen CK. Temporal analysis of the relationship of smoking behavior and urges to mood states in men versus women. Nicotine Tob Res. 2001;3(3):235-48.

42. Pomerleau CS, Brouwer RJ, Pomerleau OF. Emergence of depression during early abstinence in depressed and non-depressed women smokers. J Addict Dis. 2001;20(1):73-80.

43. Araujo RB, Castro MGT, Pedroso RS, Miguel AC, Oliveira MS. Craving e prontidão para mudança em mulheres adultas jovens dependentes do tabaco. Psico (Porto Alegre). 2010;41(2):168-75.

44. Haller DL, Miles DR, Cropsey KL. Smoking stage of change is associated with retention in a smoke-free residential drug treatment program for women. Addict Behav. 2004;29(6):1265-70.

45. Araujo RB, Oliveira MS, Pedroso RS, Miguel AC, Castro MGT. Craving e dependência química: conceito, avaliação e tratamento. J Bras Psiquiatr. 2008;57:57-63. 